\title{
Exploring DNA Methylation of MYLK as a Contributor to Acute Respiratory Distress Syndrome Disparities
}

\section{Keely Szilagyi ${ }^{1,2}$, Joe GN Garcia ${ }^{2,3}$ and Wei Zhang ${ }^{2,4^{*}}$}

${ }^{1}$ Biologic Resources Laboratory, USA

${ }^{2}$ Institute for Personalized Respiratory Medicine, USA

${ }^{3}$ Section of Pulmonary, Critical Care, Sleep, and Allergy, Department of Medicine, USA

${ }^{4}$ Department of Pediatrics, University of Illinois, Chicago, Illinois, USA

Acute Respiratory Distress Syndrome (ARDS) affects approximately 200,000 people annually in the United States with a substantial mortality rate at $\sim 40 \%$ [1]. The epidemiology of ARDS is defined by ethnicity, sex, age and modifiable risk factors such as smoking history and alcohol use. Specifically, the mortality rate among persons of African Descent (AD) with ARDS is significantly higher than persons of European Descent (ED) with ARDS, after controlling for socioeconomic status and access to healthcare, indicating a potential genetic influence on outcome $[2,3]$. However, after adjusting for severity of illness this association disappears in some studies [3,4], and AD individuals might be protected against the development of ARDS in trauma cases [4]. There has been extensive research exploring the underlying mechanisms of these health disparities in ARDS, but the specific processes remain unclear.

Previous studies using the candidate gene approach have implicated genes involving endothelial and epithelial permeability in ARDS. One comprehensively studied candidate gene is MYLK (encoding myosin light chain kinase or MLCK), an isoform (nmMLCK: non-smooth muscle MLCK) involved in vascular endothelial cell gap formation and vascular leakage, as well as implicated in the inflammatory responses including apoptosis and leukocyte diapedesis $[5,6]$. The results from both in vivo [7-10], ex vivo $[11,12]$ and in vitro $[13,14]$ studies provide solid evidence for the role of nmMLCK in the pathogenicity and susceptibility of ARDS. In order to investigate whether the genetic variants in MYLK might contribute to the health disparities associated with ARDS, several case-control studies have been performed to compare $\mathrm{AD}$ and $\mathrm{ED}$ populations. In particular, population-specific SNPs (single nucleotide polymorphisms) in MYLK exist between $\mathrm{AD}$ and ED individuals with ARDS, as well as severe asthma [15], suggesting a potential genetic contribution to lung health disparities $[16,17]$. The precise function of these genetic variants is unknown, however the knowledge of these variations allow for further research into the mechanisms of ARDS and relevant disease processes. For example, specific SNPs located in the promoter region of MYLK are associated with MYLK expression [18], thus potentially contributing to the health disparities through the differential allele frequency of the functional allele in a particular population. However, gene expression is such a complex trait or phenotype that is controlled by various genetic and non-genetic factors. More recently, epigenetic mechanisms including DNA methylation and histone modifications have begun to be investigated for their roles in regulating quantitative gene expression. A comprehensive investigation of these epigenetic mechanisms for their relationships with MYLK expression and their variation between human populations may provide novel insights into the underlying genetic basis of the health disparities in ARDS.

One highly viable epigenetic mechanism is DNA methylation, which is covalent modification typically at CpG dinucleotides across the human genomes. It has been found that silenced genes often have promoter regions with greater numbers of methylated cytosines than actively transcribed genes, suggesting that DNA methylation is a factor in transcriptional repression [19,20]. DNA methylation is also found in gene bodies, which may represent additional gene regulatory locations, possibly through regulating chromatin structure and accessibility of transcription machinery [21-23]. DNA methylation is a stable, mitotically inheritable trait that is maintained by DNA methyltransferase (DNMT1) and new methylation occurs mainly via DNA methylation enzymes DNMT3A, DNMT3B and DNMT3L [24]. Utilizing high throughput microarray technologies, recent studies have demonstrated significant natural variation in DNA methylation between human populations. For example, a previous study using the Illumina Infinium HumanMethylation $27 \mathrm{~K}$ array (covering $~ 27,000$ promoter CpGs) reported a substantial proportion ( 30\%) of population-specific CpGs between individuals of African and European ancestry [25].

More recently, the availability of the Illumina $450 \mathrm{~K}$ array (covering more than 450,000 CpGs) has allowed a much more comprehensive scan of the human genome (covering promoter regions, gene bodies, Untranslated regions [UTRs], and intergenic regions) for population variation in DNA methylation using the HapMap CEU (Caucasian residents from Utah, USA) and YRI (Yoruba people from Ibadan, Nigeria) samples [23]. Similar to Fraser et al, a substantial proportion of CpG sites (13\%) showed population-specific DNA methylation levels at a False Discovery Rate (FDR) of $1 \%$ using the $450 \mathrm{~K}$ array data [23]. Particularly, significant cytosine modification variation in MYLK was identified between the CEU and YRI samples using the 450K array data. Out of the 52 total CpGs profiled on the $450 \mathrm{~K}$ array for MYLK, eight $\mathrm{CpGs}$ were found to differentially methylated between individuals of African and European ancestry at FDR $<1 \%$. Furthermore, local (e.g., within $100 \mathrm{~kb}$ ) SNPs were identified to be associated with all eight population-specific CpGs, suggesting that the underlying genetic variation may contribute to the cytosine modification variation in MYLK. For example, the allele C of an intronic SNP in MYLK (rs6438808) was associated with a gene-body CpG (Illumina probe ID: cg12235788) in MYLK. Understanding the potential contribution of these population-specific CpGs in ARDS patients may advance the interpretation of factors that contribute to the health disparities observed in ARDS.

In summary, MYLK, a candidate gene involving endothelial and epithelial permeability is a critical participant in the pathogenesis of ARDS. The genetic variation in MYLK may account for the observed health disparities in ARDS between human populations. Technical advances have allowed exploring further gene regulatory mechanisms, such as DNA methylation variation in MYLK among patients from different populations, thus enhancing our knowledge of the underlying mechanism for ethnical disparities in ARDS.

*Corresponding author: Wei Zhang, Ph.D., Assistant Professor of Pediatrics, University of Illinois, Chicago, Illinois 60612, USA, E-mail: weizhan1@uic.edu

Received May 28, 2013; Accepted May 30, 2013; Published June 02, 2013

Citation: Szilagyi K, Garcia JGN, Zhang W (2013) Exploring DNA Methylation of MYLK as a Contributor to Acute Respiratory Distress Syndrome Disparities. J Pulm Respir Med 3: e127. doi:10.4172/2161-105X. 1000e127

Copyright: (C) 2013 Szilagyi K, et al. This is an open-access article distributed under the terms of the Creative Commons Attribution License, which permits unrestricted use, distribution, and reproduction in any medium, provided the original author and source are credited. 
Citation: Szilagyi K, Garcia JGN, Zhang W (2013) Exploring DNA Methylation of MYLK as a Contributor to Acute Respiratory Distress Syndrome Disparities. J Pulm Respir Med 3: e127. doi:10.4172/2161-105X. 1000e127

\section{Acknowledgements}

This work is partially supported by NIH grants: HG006367 and HL058064

\section{References}

1. Rubenfeld GD, Caldwell E, Peabody E, Weaver J, Martin DP, et al. (2005) Incidence and outcomes of acute lung injury. N Engl J Med 353: 1685-1693.

2. Erickson SE, Shlipak MG, Martin GS, Wheeler AP, Ancukiewicz M, et al. (2009) Racial and ethnic disparities in mortality from acute lung injury. Crit Care Med 37: 1-6.

3. Moss M, Mannino DM (2002) Race and gender differences in acute respiratory distress syndrome deaths in the United States: an analysis of multiple-cause mortality data (1979- 1996). Crit Care Med 30: 1679-1685.

4. Ryb GE, Cooper C (2010) Race/ethnicity and acute respiratory distress syndrome: a National Trauma Data Bank study. J Natl Med Assoc 102: 865869.

5. Meyer NJ, Garcia JG (2007) Wading into the genomic pool to unravel acute lung injury genetics. Proc Am Thorac Soc 4: 69-76.

6. Garcia JG, Lazar V, Gilbert-McClain LI, Gallagher PJ, Verin AD (1997) Myosin light chain kinase in endothelium: molecular cloning and regulation. Am J Respir Cell Mol Biol 16: 489-494.

7. Wainwright MS, Rossi J, Schavocky J, Crawford S, Steinhorn D, et al. (2003) Protein kinase involved in lung injury susceptibility: evidence from enzyme isoform genetic knockout and in vivo inhibitor treatment. Proc Natl Acad Sci U S A 100: 6233-6238.

8. Mirzapoiazova T, Moitra J, Moreno-Vinasco L, Sammani S, Turner JR, et al. (2011) Non-muscle myosin light chain kinase isoform is a viable molecular target in acute inflammatory lung injury. Am J Respir Cell Mol Biol 44: 40-52.

9. Parker JC (2000) Inhibitors of myosin light chain kinase and phosphodiesterase reduce ventilator-induced lung injury. J Appl Physiol 89: 2241-2248.

10. Moitra J, Evenoski C, Sammani S, Wadgaonkar R, Turner JR, et al. (2008) A transgenic mouse with vascular endothelial over-expression of the non-muscle myosin light chain kinase-2 isoform is susceptible to inflammatory lung injury: role of sexual dimorphism and age. Transl Res 151: 141-153.

11. Xu J, Gao XP, Ramchandran R, Zhao YY, Vogel SM, et al. (2008) Nonmuscle myosin light-chain kinase mediates neutrophil transmigration in sepsis-induced lung inflammation by activating beta2 integrins. Nat Immunol 9: 880-886.

12. Tauseef M, Knezevic N, Chava KR, Smith M, Sukriti S, et al. (2012) TLR4 activation of TRPC6-dependent calcium signaling mediates endotoxin-induced lung vascular permeability and inflammation. J Exp Med 209: 1953-1968.

13. Dudek SM, Birukov KG, Zhan X, Garcia JG (2002) Novel interaction of cortactin with endothelial cell myosin light chain kinase. Biochem Biophys Res Commun 298: 511-519.

14. Garcia JG, Davis HW, Patterson CE (1995) Regulation of endothelial cell gap formation and barrier dysfunction: role of myosin light chain phosphorylation. $J$ Cell Physiol 163: 510-522.

15. Flores C, Ma SF, Maresso K, Ober C, Garcia JG (2007) A variant of the myosin light chain kinase gene is associated with severe asthma in African Americans. Genet Epidemiol 31: 296-305.

16. Christie JD, Ma SF, Aplenc R, Li M, Lanken PN, et al. (2008) Variation in the myosin light chain kinase gene is associated with development of acute lung injury after major trauma. Crit Care Med 36: 2794-2800.

17. Gao L, Grant A, Halder I, Brower R, Sevransky J, et al. (2006) Nove polymorphisms in the myosin light chain kinase gene confer risk for acute lung injury. Am J Respir Cell Mol Biol 34: 487-495.

18. Han YJ, Ma SF, Wade MS, Flores C, Garcia JG (2012) An intronic MYLK variant associated with inflammatory lung disease regulates promoter activity of the smooth muscle myosin light chain kinase isoform. J Mol Med (Berl) 90: 299308.

19. Attwood JT, Yung RL, Richardson BC (2002) DNA methylation and the regulation of gene transcription. Cell Mol Life Sci 59: 241-257.

20. Deaton AM, Bird A (2011) CpG islands and the regulation of transcription Genes Dev 25: 1010-1022.

21. Jones PA (2012) Functions of DNA methylation: islands, start sites, gene bodies and beyond. Nat Rev Genet 13: 484-492.

22. Portela A, Esteller M (2010) Epigenetic modifications and human disease. Na Biotechnol 28: 1057-1068.

23. Moen EL, Mu W, Delaney SM, Wing C, McQuade J, et al. (2012) Differences in DNA methylation between the African and European HapMap populations. Proceedings: AACR 103rd Annual Meeting.

24. Rodriguez-Osorio N, Wang H, Rupinski J, Bridges SM, Memili E (2010) Comparative functional genomics of mammalian DNA methyltransferases. Reprod Biomed Online 20: 243-255.

25. Fraser HB, Lam LL, Neumann SM, Kobor MS (2012) Population-specificity of human DNA methylation. Genome Biol 13: R8. 